\title{
Correction to: Coupled Thermal-Mechanical Progressive Damage Model with Strain and Heating Rate Effects for Lightning Strike Damage Assessment
}

\author{
S. L. J. Millen ${ }^{1} \cdot$ A. Murphy ${ }^{1}$ D $\cdot$ G. Catalanotti ${ }^{2} \cdot$ G. Abdelal $^{1}$
}

Published online: 9 November 2020

(c) Springer Nature B.V. 2020

\section{Correction to: Applied Composite Materials (2019) 26:1437-1459 \\ https://doi.org/10.1007/s10443-019-09789-z}

The original version of this article unfortunately requires correction with respect to the affiliations of the authors. The correct affiliations are now reflected in the affiliation section of this Correction (Erratum) paper.

Publisher's Note Springer Nature remains neutral with regard to jurisdictional claims in published maps and institutional affiliations.

The online version of the original article can be found athttps://doi.org/10.1007/s10443-019-09789-z.

A. Murphy

a.murphy@qub.ac.uk

1 School of Mechanical and Aerospace Engineering, Queen's University Belfast, Ashby Building, Belfast BT9 5AH, Northern Ireland, UK

2 Advanced Composites Research Group (ACRG), School of Mechanical and Aerospace Engineering, Queen's University Belfast, Belfast BT9 5AH, UK 